\title{
PSICOLOGÍA E IMÁGENES: EL PROCESO DE NARRACIÓN DIGITAL EN LA INVESTIGACIÓN SOBRE LA IDENTIDAD EN LA INFANCIA EN RIESGO DE EXCLUSIÓN
}

\begin{abstract}
Psychology and Images: The Process of Digital Narration in the Investigation on the Identity in the Childhood in Exclusion Risk
\end{abstract}

Adolfo Pizzinato*

Recibido: 25 de julio de 2008 - Revisado: 22 de agosto de 2008 - Aprobado: 8 de septiembre de 2008

\section{Resumen}

En este trabajo se discuten algunos aspectos teóricos y metodológicos del uso de las producciones narrativas digitales como material de análisis para la investigación psicológica sobre la identidad. El foco del trabajo presentado está en la infancia en riesgo de marginación social, étnica y educativa, presentando un análisis de propuesta de intervención psicoeducativa basada en el aprendizaje colaborativo, intercultural e intergeneracional.

* Psicólogo, Doctor en Psicología de la Educación por la Universitat Autónoma de Barcelona (UAB). Profesor del Curso de Psicología de la Universidade Luterana do Brasil (ULBRA) y de la Facultad de Psicología de la Pontifícia Universidade Católica do Rio Grande do Sul (PUCRS). Correo electrónico: adolfo.pizzinato@pucrs.br. 


\title{
Palabras clave
}

Psicología e imágenes, narrativas digitales, infancia.

\begin{abstract}
In this work some theoretical and methodological aspects of the use of digital narrative productions like material of analysis for the psychological investigation on the identity are discussed. The center of the work is in the childhood in risk of social, ethnic and educative marginalization, presenting an analysis of proposal of psychological educational intervention based on the collaborative, intercultural and intergenerational learning.
\end{abstract}

\section{Key words}

Psychology and images, digital narratives, childhood.

Este artículo se presenta como el análisis del uso metodológico de la producción de imágenes en la investigación psicológica. Este relato se basa en una experiencia de intervención psicoeducativa en una escuela de la región metropolitana de Barcelona, donde la producción colaborativa de películas se ha ido constituyendo en una herramienta fundamental para la producción de una discusión sobre (y una producción de sentidos) las identidades de los participantes. Pretenderse aquí, además de presentar un modelo de actividad basada en el aprendizaje colaborativo, discutir algunos aspectos del proceso de inserción de una propuesta como está en una escuela con bajos niveles de éxito académico, en un barrio con alto riesgo de exclusión social y cultural.

Así, además de producir sentidos identitarios que a través de otros procesos investigativos no se obtendrían -una vez que aquí se trabajara desde una perspectiva narrativa de identidad-, el uso de la producción de imágenes e historias también ha servido como una herramienta de inclusión (real de sentido) en el ámbito educacional formal catalán.

Como propone Bruner (1998) -y el modelo de hombre de la Psicología Cultural-, la estructura escolar es muy moldeada por la cultura que la rodea, y así, conserva una tendencia a dominar y a dirigir los movimientos de nueva organización interna y la emergencia de nuevos sistemas de frontera de conocimiento dentro de la institución educativa. Estos sistemas deberían actuar como redes de apoyo, normalmente temporales, que de alguna manera buscan potenciar el aprendizaje colaborativo dentro del sistema de la actividad y bajo una perspectiva sociocultural.

Las actividades basadas en la concepción de los niños y niñas como creadores de cultura y de conocimiento son bastante distintas de las concepciones más tradicionales de la infancia y su relación con el aprendizaje y la cultura. En esta visión de la infancia, como competente y curiosa, está un niño o niña que está lleno de ganas de aprender, de explorar y de desarrollarse como un ser humano en relación activa con las otras personas. Los niños y las niñas son vistos como poseedores de recursos y tomando una posición activa en el proceso de producción del conocimiento. Este niño o niña es activo en la construcción de sí mismo, su personalidad y conocimientos y habilidades a través de la interacción con el ambiente.

Podemos promover el aprendizaje cooperativo para que apoye el desarrollo cognitivo individual o para que el mundo exterior a la escuela recompense estas destrezas, pero también podemos favorecerlo, porque creamos, sin más, que la actividad intelectual conjunta sea 
una dimensión satisfactoria de la experiencia humana (Crook, 1998). Sólo la dimensión cognitiva no justificaría todo el proceso de aprendizaje colaborativo, como se ha implantado, buscando un diálogo auténtico con todos los participantes y sus expectativas.

Se ha trabajado en una escuela en diferentes proyectos y el nuevo reto era presentar una actividad en la cual los niños y niñas construyeran una "historia digital". Esta actividad se ha llevado a cabo durante todo un curso lectivo, en horario extra escolar con seis grupos de niños de once y doce años. Las construcciones de las diferentes historias han sido llevadas a término por pequeños grupos formados por dos o tres niños y un adulto (estudiantes de prácticas de psicología). De esta manera, además de proponerse una actividad colaborativa, en tanto proceso de investigación, también se producía un momento intercultural, intergeneracional $y$, a la vez, formativo para todos los segmentos implicados -integrando formación e investigación.

Los temas de interés, la planificación y la organización surgieron a partir de un proceso de negociación dentro de los diferentes grupos. Los frutos de esta actividad han sido narrativas digitales muy distintas, con producciones que gravitan entre polos: sea entre Ios polos del lenguaje infantil a la cultura adolescente; sea entre los polos de la cultura tradicional y la narrativa globalizada al estilo hollywood.

La actividad ha sido desarrollada en un entorno social y culturalmente marginado, con predominancia de poblaciones gitanas o de inmigrantes del norte de África o del sudoeste asiático. Trobadors es una propuesta de entornos para un aprendizaje significativo, que supone explorar, crear, imaginar, jugar, reflexionar. La actividad se apoya en artefactos para facilitar varias formas de comunicación y actividades de aprendizaje $y$, a la vez, generan ideas y diseños para nuevos artefactos y actividades -tanto en términos investigativos como en términos de intervención-. La comunicación oral y escrita es un elemento fundamental, puesto que constituye la base para el diálogo entre grupos diferentes de participantes. Los ordenadores y los otros hardwares periféricos son las herramientas adecuadas por facilitar esta forma de aprendizaje cooperativo y así integrar en las bases de la investigación psicológica tanto los aspectos relacionales, como los verbales y los representados por las imágenes (documentales y ficcionales a la vez).

Un segundo objetivo que orienta el proyecto es el diseño de entornos de aprendizaje significativo para alumnos de colectivos culturales minoritarios en riesgo de (más) exclusión social. Los usos de las Tecnologías de Información y Comunicación (TIC) se presentan a través de un espacio basado en una cultura de colaboración, en la cual los significados se negocian desde el primer momento, respondiendo a los intereses y a los niveles de desarrollo potencial de los alumnos. La actividad Trobadors se justifica por tres ejes:

- Un papel activo de los niños y niñas en todo el proceso de creación. Ellos(as) son quienes deciden la temática de la historia, su contenido y los materiales que utilizarán (cámara de fotografía, de video, software de tratamiento de la información, etc.). Por consiguiente, la educación se transforma en un proceso creativo, en el cual las necesidades y la propia experiencia son las que crean los objetivos y las formas de aprender el proceso mismo de significación de los productos de este espacio de construcción.

- El trabajo intergeneracional e intercultural. Durante todo el proceso de creación los grupos se han mantenido estables, y son tanto los(as) niños(as) como los(as) adultos(as) quienes participan de la construcción de la historia, en una relación horizontal en la cual todas las voces se escuchan con la misma fuerza. Las dos miradas se confrontan en el mismo nivel, negociar en cada momento desde dónde se explicará la historia. Se crea, así, una visión híbrida entre el adulto y el niño.

- La identidad como una construcción contingente a las relaciones sociales. Como construida y actuada en cada momento en la relación con las 
otras. Desde esta perspectiva la construcción de historias digitales ofrece un nuevo escenario en el que construir identidades nuevas, representar la propia identidad y generar nuevas formas de ser. La mirada del otro aquí se hace explícita. Las historias se crean por ser explicadas, por ser presentadas a un público hipotético. El(la) autor(a) se percibe como creador(a) y sus representaciones se hacen explícitas, se toma conciencia de la visión de éstos a partir de lo que se explica.

Pero ésta no ha sido la primera propuesta de investigación psicológica que tiene en su raíz el uso de las imágenes, sean de fotografías o de video. A lo largo de los últimos años se ha observado el aumento de la discusión sobre el uso de imágenes en la investigación en ciencias humanas, en general, así como una frecuencia mayor en el uso de las tecnologías audiovisuales como recurso metodológico. La práctica de entregar una cámara de video o fotografía a personas que participan activamente de una situación para ser estudiada, se ha tornado más frecuente y ha oprimido a diferentes áreas de especialidad. Además de la Antropología Visual, que desde hace mucho trabaja con tecnologías de producción fotográfica y de video -se puede elencar a la Comunicación Social, a la Psicología, la Educación y la Sociología como áreas que inverten en el estudio de la producción de imágenes como recurso metodológico (Kirst, 2000; Maurente, 2005; Maurente \& Tittoni, 2007; Neiva-Silva, 2003).

Las innovaciones tecnológicas de producción y reproducción de imágenes serían herederas del ideario de la modernidad, que dirige una mirada humana sobre el mundo, cuya finalidad es observar y disecar la realidad para mejor describirla e intentar dominarla. Si la existencia de lo que está en la fotografía es innegable, en compensación, lo que la fotografía significa, su sentido, es construido de manera totalmente convencional y cultural por el juego de todos estos parámetros (Maurente \& Tittoni, 2007).

Neiva-Silva (2003) ha realizado una investigación basada en la utilización del método auto fotográfico. De acuerdo con él, este método ha sido descrito inicialmente por Robert Ziller, en los finales de la década del setenta y consiste en solicitar a la persona que produzca y presente algunas imágenes al investigador, describiendo su visión de un ambiente, o realidad particular o de sí mismo.

Las imágenes así producidas poseen la ventaja de documentar la percepción de los participante, con un mínimo de entrenamiento, evitando las desventajas usuales de las técnicas de relato verbal. Incluso, los autores resaltan la ventaja de no ser el investigador el que guía la mirada del participante hacia determinada categoría de respuesta, siendo el mismo participante el que elige los estímulos. A pesar de que este tipo de investigación se distancie de los primeros usos que la psicología hizo de la fotografía (en el sentido de proponer una valorización del saber del participante), o método auto fotográfico sigue aun buscando la utópica "neutralidad". Pero es importante destacar que parece haber una nueva manera de pensar el uso la fotografía en psicología, pues cada vez menos las imágenes figuran en las investigaciones como meros "registros de lo 'real'", pero ya como una construcción y una perspectiva alternativa de lenguaje en investigación humana (Maurente \& Tittoni, 2007).

Las imágenes en la producción científica han sido tratadas por Barthes (1984) como un elemento que se escapa de la clasificación y de la generalización y, por lo tanto, produce cierto desorden, que es originado por el hecho de que la imágenes, a la vez que designan la "realidad" -ya que "repiten mecánicamente lo que nunca más podrá repetirse existencialmente" ( $p$. 13)-, son invisibles per se, pues su referente se adhiere a ellas y solamente podrán ser vistas a través de él. Como bien sitúan Maurente y Tittoni (2007), este desorden y este dilema impiden cualquier reduccionismo y hacen que el tema de las imágenes en la producción científica se moldee en otros espacios y pesen las presiones traídas por la lógica cientificista.

La experiencia de investigación con imágenes, sean fotográficas, cinematográficas o televisivas, surge en 
la mayor parte de las veces de manera espontánea, intermitente y fragmentada. Con la proliferación de las imágenes, cada día ellas se afrontan con el riesgo de perder su capacidad de decir algo a alguien, pues también las personas que viven esa dispersión perceptiva de modo permanente acaban por perder la sensibilidad para ver las cosas, viéndolas como signos, extrayendo sentidos diferenciados de la materialidad del mundo y de los significados incorporados culturalmente a las imágenes que nos rodean.

La experiencia desarrollada en Barcelona, con la producción de historias digitales (de carácter cinematográfico), tenía como objetivo producir un espacio de construcción colaborativa de "saberes" en la escuela, sobre todo, utilizando las TIC como herramienta (real y simbólica) para la promoción de actividades psicoeducativas que promovieran la inserción escolar (y por lo tanto social) de niños y niñas en riesgo de exclusión étnico-cultural. Los resultados de la experiencia indican que la cultura parece ejercer cierto papel de "educadora estética", lo que promueve la elección de temas, formas de captación de imágenes y scripts de actuación.

La educación estética lleva a pensar sobre las contribuciones del arte y de la cultura en el proceso educativo. El arte es una producción social y un campo de conocimiento específico que puede revelar otros modos de ver y comprender la realidad. Su presencia en el contexto educacional contribuye para ampliar las posibilidades de interacción del alumno y del maestro con ese campo que supone la producción y el disfrute estética/artística.

La producción colectiva, implicando alumnos de distintos orígenes étnico-culturales, sociales, géneros y apropiación de las herramientas culturales de la actividad y de la escuela, produjo resultados importantes en la identificación del cruce identitário en el que viven. Como es característico de la contemporaneidad, las identidades son fluidas y poli facetadas, tal como sugieren las producciones de películas de los participantes, que mezclan aspectos locales con globales o los típicos de la niñez con los típicos de la adolescencia.

En la tensión establecida entre el convivir de distintos puntos de vista y modos de ver, se encuentra la riqueza de la experiencia estética compartida. Un aprendizaje estético realmente colaborativo objetiva desvelar, ampliar y proponer desafíos a partir de experiencias lúdicas, cognitivas y narrativas que impliquen el arte y los demás campos del saber. El investigador ejerce un importante papel de mediador en este tipo experiencia, en la que busca ampliar el contacto más crítico del participante con las formas y lenguajes artísticos, culturalmente construidas, aunque muchas veces parezcan contradictorios, sobre todo si se considera el ámbito de la infancia.

Pero si la producción del conocimiento en la infancia (a través de imágenes) no dispensa la capacidad de dialogar con los aparatos tecnológicos, cabe tanto al investigador como a los demás participantes de la investigación que implique la producción de imágenes construir, con esos aparatos tecnológicos, nuevas posibilidades de usos, poniendo las máquinas y las herramientas a nuestro poder y deseo de inventar otras maneras aun no reveladas en la práctica. Por lo tanto, se trata de crear, por medio de la investigación, maneras de afrontar la experiencia tecnológica, poniendo a todos los implicados en una posición de percibir como responsables por inventar otras estrategias de interacción en la producción del conocimiento. Eso implica decir que la intervención mediada por la tecnología es un juego, pues cada vez más las máquinas se transforman en aparatos para que también se recupere una dimensión lúdica en la producción del conocimiento, que de hecho es trabajo.

Si se comparan los adultos y los niños y niñas en esas actividades, con frecuencia, constatamos un modo más distendido y familiar de los niños y niñas con la tecnología, incluso, muchos adultos logran en situaciones similares, lo que también justifica el uso de las TIC y la producción de imágenes como herramienta de la investigación psicológica en la infancia. 
Además en la experiencia llevada a cabo en Trobadors, la confrontación entre generaciones amplía el campo de las experiencias creadoras. Los "saberes" de niños y niñas, en contacto directo con los conocimientos barajados por los adultos, es un campo fértil para descubrimientos que pueden ocurrir en un clima de auténtica libertad, lo que privilegia las maneras de ser, actuar y conocer de cada uno(a). Así, el espacio en el que ocurre una investigación también puede ser entendido como un espacio de construcción de un (o muchos) yoes, a través de una interpretación narrativa del proceso de creación de las imágenes y de las imágenes en sí mismas.

De manera consonante con el "giro" lingüístico vivido por las ciencias sociales en la contemporaneidad, las instituciones se pueden entender como un espacio discursivo constituido a través de las prácticas de lenguaje y en particular en contar y recontar "historias". Las identidades desarrolladas en estos entornos discursivos son múltiples y pueden ser complementarias, competentes, contradictorias, distintas o próximas, hegemónicas o no, pero es en la confluencia de muchas de las narrativas identitárias individuales que se construye una identidad colectiva compartida, como puede ser la de una escuela o comunidad (Brown, Humphreys \& Gurney, 2005).

Las narrativas (imagísticas o no) pueden ser entendidas como relatos cargados de valor simbólico, de maneras activas e involucradas por palabras que incorporan secuencia, tiempo y lugar, constitutivas de las identidades sociales y personales. El énfasis se debe poner en la acción social en la que sucede o en la naturaleza de la construcción de las descripciones y relatos, que hacen las personas cuando utilizan recursos particulares en los relatos (Verkuyten \& de Wolf, 2002).

Las identidades individuales y colectivas tienen su autoría dentro de un régimen discursivo que proviene de los actores sociales con importantes recursos simbólicos por la negociación de la identidad. Estos recursos pueden ser posiciones o espacios para ocupar. Las identidades narrativas no son estáticas y no se completan nunca. Están en constante proceso de ser "complementadas", asimiladas, mezcladas, refinadas, elaboradas y sumergidas en "un todo" de historias que se regulan y se construyen unas a las otras (Verkuyten \& de Wolf, 2002). La idea que las identidades individuales son subjetivamente evaluables a través de las narraciones de las experiencias que comunican, tiene un sentido de unicidad biográfica, y es ahora muy consolidada (Verkuyten \& de Wolf, 2002). Según la idea de Bruner (1997), las personas se vuelven quién son a través de contar historias sobre sus vidas y vivir las historias que cuentan en los espacios territoriales y temporales en que viven. Estos espacios, o marcadores, pueden ser entendidos como puntos clave para el entendimiento de la identidad contemporánea, tanto en su dimensión psicológica más narrativa, como en su dimensión psicosocial e histórica.

Como representaciones de experiencias complejas reducidas al lenguaje, al sonido y a las imágenes, las historias funcionan como herramientas simbólicas, formas de entender la experiencia como un despliegue en tiempo y espacio (Bruner, 1997). Bajtin desarrolló una teoría "dialógica" que conectaba la experiencia de vida con la autoría; asimismo, propuso que el lenguaje y los géneros se presentan a las personas a través de la participación cultural y se volvían las bases de significado por las cuales se interpretará y se responderá al mundo (Davis, 2004). Las respuestas que se dan a los mensajes de cada momento de la existencia son como un proceso autoral en primera persona. Cada persona es autora de su propia historia y como en cada acto autoral, la elección y la interpretación son imprescindibles. Pero también cada acto de autoría es un acto de coautoría. Las palabras e interpretaciones disponibles por las personas originalmente no pertenecen a estas personas, pero sus historias están presentes en la interacción con los otras y sus palabras y actos ubican los autores y las interpretaciones asertivas por las que responden los autores, proceso mucho más fluido en la producción de narrativas con el uso de imágenes, más propicias a imprevisibles desdoblamientos de la subjetividad (Davis, 2004). 
En este sentido, el aprendizaje y la investigación pueden ser transformadores, así como adicionales: se aprende de la experiencia cuando se internalizan representaciones simbólicas dibujadas por la propia experiencia; éstas, alternadamente, permiten transformaciones cualitativas en la forma de actuar de una por otra (Vygotsky, 1997). La narrativa es un medio por el cual se aprende de la experiencia y a través de su reflexión, declarando qué significa y "destilando" este significado en una manera simbólica para ser expresada y recordada (Davis, 2004). Este proceso es esencialmente flexible y se despliega en sí mismo; la experiencia es transformada en narrativa y la narrativa en sí misma se transforma en una herramienta que da forma a la memoria y a las experiencias futuras inmediatas.

Pero como la autoría se da en la interacción con los demás -"otros", aquéllos que incluso pueden confirmar quién es el autor y nutrirlo de interpretaciones, o incluso ser sólo "simbólicos" -, se deriva en un aspecto político, un aspecto que rodea el habilitado en ponerse y de dar forma al contar su propia historia. Pero, ¿quien puede explicar una historia?, ¿los demás cómo la interpretan o la responden?, ¿qué partes de la historia son silenciadas por las ideologías dominantes? Éstas son las preguntas que formula Davis (2004) y que pertenecen a la construcción de la identidad en las múltiples palabras e imágenes en que el autor actúa y también en el contexto directo de la autoría.

Los estudios que buscaban aliar la comprensión de la subjetividad en la formación del análisis narrativo, comparten la visión de que el lenguaje tiene un papel central como la expresión de la identidad y como constitutiva de la experiencia humana en el mundo. El sentido de identidad se expresa en la formación de historias, bien sean vividas, contadas, recontadas, representadas e intersubjectivamente transformadas. Este carácter "historiado" de la identidad permite referirse a ella como identidad narrativa; las historias contadas por una persona son simultáneamente una práctica social y están dirigidas a una audiencia, estructuradas con base en una lengua o imágenes por las cuales la persona vuelve pública la experiencia privada, y cuentan creencias, valores e ideologías, proviniendo del contexto sociocultural; asimismo, es una actividad auto epistémica (Wortham, 2000), por medio de la cual la persona se reconoce y se transforma, cuando engendra nuevos significados y comportamientos y cuando se toma posición ante ellos, desde una perspectiva ética.

De esta forma, el abordaje de las prácticas narrativas explora su dimensión de creación de la novedad, narrar como acto de emergencia, por oposición al lenguaje como ventana por la mente y la narración como acto de revelación de una subjetividad preexistente (Lopes de Oliveira, 2006). De la manera como se entiende aquí, las narrativas constituyen el contexto micro genético en que las personas se presentan públicamente y se constituyen, contra el telón de fondo dado por el contexto socio institucional en que se inserta la interacción, un sentido de sí sustentado ínter subjetivamente (Korobov \& Bamberg, 2004). En el contexto de las interacciones discursivas, las personas desarrollan estrategias retóricas que darán el apoyo necesario para la constitución de un sentido de sí, al mismo tiempo imaginario (sostenido en imágenes sociales y personales) y discursivo. Estas estrategias todavía buscan garantizar que el otro social, en el contexto ínter subjetivo, interprete de forma coherente con su proyecto subjetivo (Bamberg, 2004).

\section{Conclusiones}

Como escenario del sentido de sí, las narrativas y las imágenes son el contexto del cruce de temporalidades y en permanente tensión entre la ilusión de continuidad; la coherencia temporal y el tiempo vivido; experiencial, cíclico, ilógico, por un lado, la ilusión de continuidad (identidad) preservando la noción de que se es una misma persona, a pesar de los profundos cambios que cada uno pasa en el ciclo del desarrollo; de otra manera, el paso del tiempo (desarrollo) como la propia condición de inteligibilidad de la narrativa (Lopes de Oliveira, 2006). 
En el proceso de descubrir cómo la identidad es generada por la combinación de la persona, cultura y práctica y el rol que las instituciones producen puede ser particularmente interesante, cuando involucran dos propiedades mayores (Lacasa, del Castillo \& GarcíaVarela, 2005). La primera es su estructura y organización, en contextos específicos, como por ejemplo, las escuelas; las personas organizan sus relaciones de acuerdo con los roles y con las normas que obligan las acciones de cada individuo. La segunda son las instituciones, que pueden estar relacionadas con las obligaciones que tienen como actores de sedes propios grupos, y esto se produce en el contexto en que se generan conceptos y valores que guían las prácticas sociales (Lacasa, del Castillo \& García-Varela, 2005). Por lo tanto, en esta misma dirección, la presente revisión pretende comprender la relación entre los aspectos narrativos de la construcción de la identidad, por lo que se consideran los aspectos culturales, socio cognitivos, lingüísticos, imagísticos e institucionales que interactuaron en la formación de una conciencia del self, en una propuesta que considera la interfaz de la psicología con el tiempo, el espacio y el contexto de producción de significados compartidos a través de la producción de imágenes.

\section{Referencias}

Bamberg, M. (2004). Form and Functions of "Slut-Bashing" in Male Identity Constructions in 15-YearsOlds. Human Development, 249, 331-353.

Barthes, R. (1984). A câmara clara. Rio de Janeiro, RJ: Nova Fronteira.

Brown, A.; Humphreys; M. \& Gurney, P. M. (2005). Narrative, Identity and Change: A Case Study of Laskarina Holidays. Journal of Organizational Change Management, 18 (4), 312-326.

Bruner, J. (1997). La educación, puerta de la cultura. Madrid: Visor.
Bruner, J. (1998). Actos de significado. Alianza.

Crook, C. (1998). Ordenadores y aprendizaje colaborativo. Madrid: Morata.

Davis, A. (2004). Co-authoring identity: digital storytelling in an urban middle school. Then - Technology, Humanities, Education and Narrative. Recuperado el 12 de octubre de 2007 de: http://thenjournal. org/feature/61/.

Kirst, P. (2000). Fotográfico e subjetivação: Hibridização, multiplicidade e diferença. Tesis de maestría no publicada, Programa de Pós-Graduação em Psicologia Social, Universidade Federal do Rio Grande do Sul, Porto Alegre, RS.

Korobov, N. \& Bamberg, M. (2004). Positioning a "Mature" Self in Interactive Practices. How Adolescent Males Negociate 'Physical Attraction' in a Group Talk. British Journal of Developmental Psychology, 22, 471-492.

Lacasa, del Castillo \& García-Varela. (2005). A Bakhtinian Approach to Identity in the Context of Institutional Practices. Culture \& Psychology, 11 (3), 287-308.

Lopes de Oliveira. (2006). Identidade, narrativa e desenvolvimento na adolescência: uma revisão crítica. Psicologia em Estudo, 11 (2), 427-436.

Maurente, V.S. (2005). A experiência de si no trabalho nas ruas através da fotocomposição. Tesis de maestría no publicada, Programa de Pós-Graduação em Psicologia Social, Universidade Federal do Rio Grande do Sul, Porto Alegre, RS.

Maurente, V. \& Tittoni, J. (2007). Imagens como estratégia metodológica em pesquisa: a fotocomposição e outros caminhos possíveis. Psicologia \& Sociedade, 19 (3), 23-31.

Neiva-Silva, L. (2003). Expectativas futuras de adolescentes em situacão de rua: Um estudo autofoto- 
gráfico. Tesis de maestría no publicada, Programa de Pós-Graduação em Psicologia do Desenvolvimento, Universidade Federal do Rio Grande do Sul, Porto Alegre, RS.

Verkuyten, M. \& de Wolf, A. (2002). Being, Feeling and Doing: Discourses and Ethnic Self-Definitions Among Minority Grup Members. Culture \& Psycho$\log y, 8$ (4), 371-399.
Vygotsky, L. S. (1997). Pensamento e linguagem. São Paulo: Martins Fontes.

Wortham, S. (2000). Interactional Positioning and Narrative Self-Construction. Narrative Inquiry, 10 (1), 157-184. 